\title{
A podcasting-based pre-service teacher training model
}

\author{
Jing Zhao* \\ Department of Computer Science \\ School of Information Engineering \\ Urumqi Vocational University, China \\ E-mail: zhaojing210@126.com
}

\section{Jianli Jiao}

Future Education Research Centre

School of Information Technology in Education

South China Normal University, China

E-mail: jiaojianli@126.com

*Corresponding author

\begin{abstract}
Podcasting has been increasingly used as a new approach to broadcasting information. In the educational field, podcasting offers plenty of opportunities to improve and facilitate pre-service teacher training in normal schools. This study analyses the practice of using podcasting for teaching skills training, and proposes a TSTP (Teaching Skills Training on Podcasting) model to improve the training effectiveness.
\end{abstract}

Keywords: Pre-service teacher; Training model; Podcasting; Educational technology

Biographical notes: Jing Zhao is a Master student studying Information Technology in the ITMS Department of the University of Ballarat in Australia. She received her Bachelor in Journalism from XinJiang University, China. She has fifteen years of teaching experience within Urumqi Vocational University. Her current research interests include information and multimedia technology in vocational education.

Dr. Jianli Jiao is a Professor of Educational Technology and Deputy Dean of School of Information Technology in Education, South China Normal University. He has published 4 books and more than 80 journal articles and book chapters. Dr. Jiao's research interests include learning sciences and technologies, technology enhanced teachers professional development, and Web2.0 application in teaching and learning. He received his Bachelor in Schooling and Master in Psychology from Shaanxi Normal University of China, and his Ph.D. in Educational Technology from South China Normal University.

\section{Introduction}

Teaching skills are essential parts of teachers' professional development and play important roles in teachers' daily practice in classroom. Teachers use teaching skills to design, teach and organize learning activities inside and outside classrooms. Teaching 
skills are important in promoting students' activities and their completion of learning tasks, directly affecting teaching quality (Gibbs \& Coffey, 2004). It is crucial that teaching skills training be adequately offered to per-service teachers, helping them to smoothly enter the workplace.

The development of teaching skills requires the application of general skills to the classroom setting in a variety ways such as description, demonstration, imitation and training (DeIker, 1990). With the increased applications of advanced technologies in the education field, podcasting has shown its clear advantages. Podcasting means "the authoring of, and subscription to, audio and/or video files on the Internet for downloading to the user's personal computer" (Lim, 2005). "It enables users to quickly and easily upload and download multimedia files, in terms of audio and video, for playback on mobile devices including iPods ${ }^{\mathrm{TM}}$ and other MP3 players" (Bausch \& Han, 2006). For per-service teacher training in normal schools, podcasting can effectively enhance the training process and improve students' interest and motivation. It not only uses video and audio to train students' teaching skills, but also helps students to analyze and assess training processes and results until they completely master teaching skills. Moreover, using podcasting requires little additional resources or investment on new equipments. As a result, podcasting provides a new approach to teaching skills training in the classroom. In the following sections, we will discuss the weaknesses of existing training models, and propose a podcasting-based teaching skills training model.

\section{Literature review}

Educational practice and micro-teaching are the main approaches for training per-service teachers' teaching skills. However, due to the short durations of training programs, many students have problems to acquire sufficient skills through these programs. Meanwhile, micro-teaching training pays more attention to basic and general skills in classroom, neglecting needs of individual learners (Felder \& Brent, 2005). Other models such as digital training, case-based training, and video-based training are found to be more effective in training teaching skills (Moursand \& Bielefeldt, 1999). However, they require a large amount of resources and investment on equipments, which may slow down the adoption process.

The use of podcasting, a new technology that supports learning and instruction, has been one of the hot topics in education. After reviewing existing teaching skills training models, we found that some technical features of podcasting can make up the deficiencies of exiting models and stimulate students' interest, engagement and participation. Table 1 outlines the deficiencies of the existing training models (Yang \& $\mathrm{Wu}, 1999)$, as well as the features of podcasting in training (Bausch \& Han, 2006). It shows the potential of using podcasting technologies to build a platform for training of per-service teachers. Podcasting is found to be cost-saving, easy to use, and flexible in applications. 
Table 1

Existing training models versus podcasting

\begin{tabular}{|l|l|}
\hline \multicolumn{1}{|c|}{\begin{tabular}{c}
\multicolumn{1}{|c|}{$\begin{array}{c}\text { Deficiencies in existing training } \\
\text { models }\end{array}$} \\
$\begin{array}{l}\text { Requiring more human resources, } \\
\text { equipments, and materials }\end{array}$
\end{tabular}} & $\begin{array}{l}\text { Only requiring computer, Internet access, } \\
\text { with associated audio and video } \\
\text { equipments }\end{array}$ \\
\hline $\begin{array}{l}\text { Gap between formal training mode and } \\
\text { individual learning need }\end{array}$ & $\begin{array}{l}\text { Flexible training mode supporting } \\
\text { individual need }\end{array}$ \\
\hline Insufficient formal training time & $\begin{array}{l}\text { Flexible training mode without less time } \\
\text { and space restriction }\end{array}$ \\
\hline $\begin{array}{l}\text { More emphasis on individual skill } \\
\text { training than integrated skill training. }\end{array}$ & $\begin{array}{l}\text { Facilitating systematic and comprehensive } \\
\text { training }\end{array}$ \\
\hline $\begin{array}{l}\text { Low level of participation and } \\
\text { engagement }\end{array}$ & $\begin{array}{l}\text { Facilitating higher engagement via } \\
\text { exchange, discussion, and reflection }\end{array}$ \\
\hline Difficult to retain the training process & Easy to record training files for analysis \\
\hline
\end{tabular}

\section{Design of a podcasting-based teaching skills training model}

Based on pre-service teachers' training needs, shortcomings of existing training models, and characteristics of podcasting, this study proposes a model Teaching Skills Training on Podcasting (TSTOP) model to support training in normal schools.

As shown in Fig. 1, the TSTOP model includes a number of components such as making training objectives, designing lesson plans, teaching practice, evaluation, selfreflection, and so on. To verify the effectiveness of the TSTOP model, a platform has been developed. The development process includes three stages, as shown in Fig. 2. Selected course contents were put onto the platform for training. Learners' action and performance records throughout the training process were recorded and evaluated 


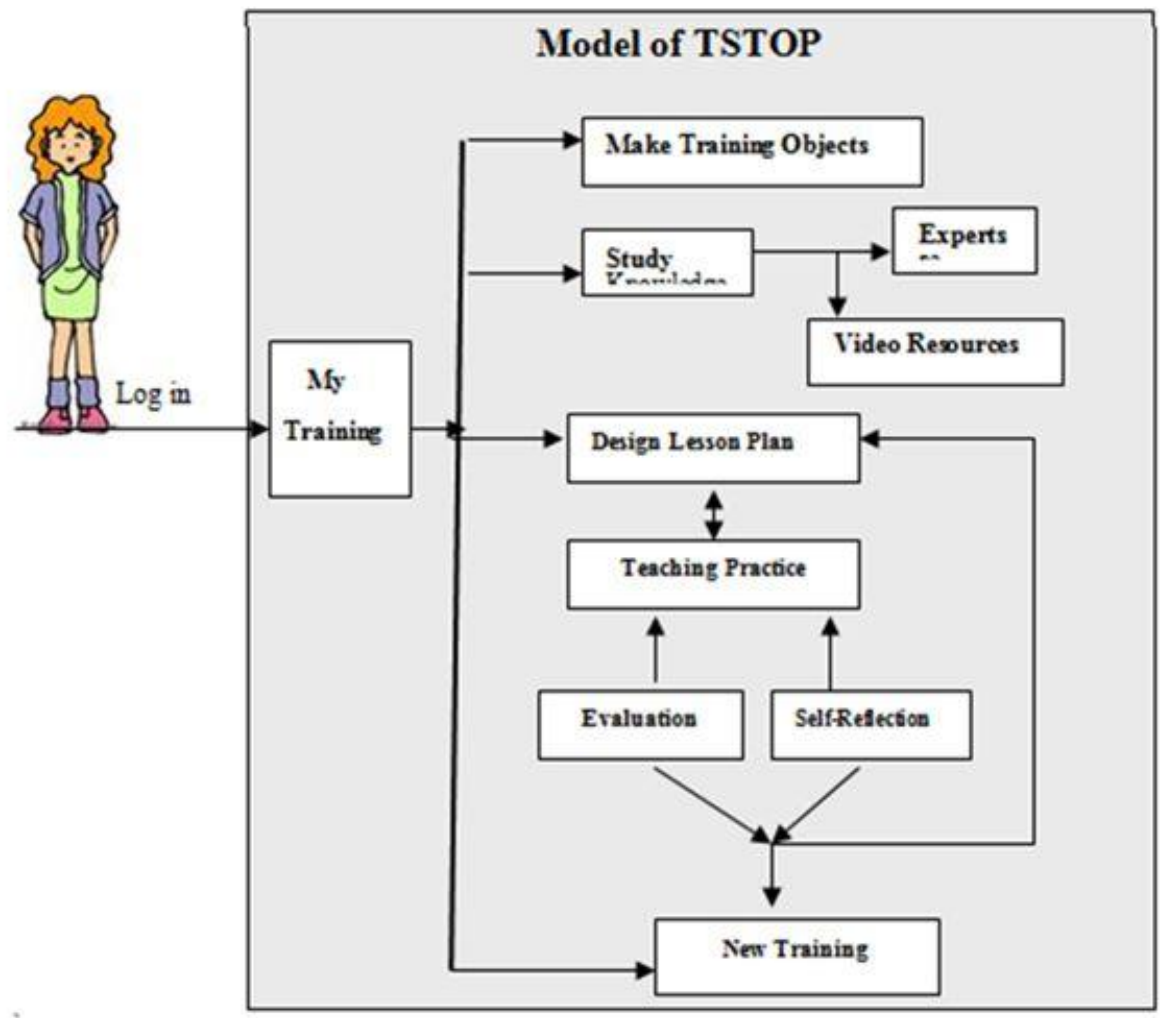

Fig. 1. The TSTOP model

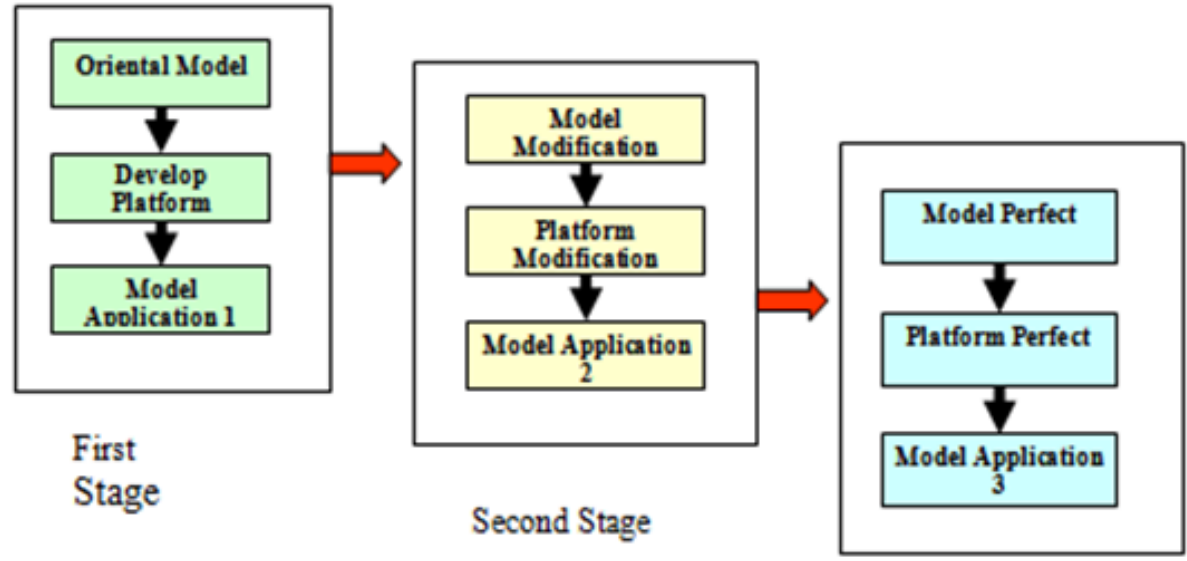

Third Stage

Fig. 2. Design and development procedure of the TSTOP platform 


\section{Research method and procedure}

\subsection{Data collection and participants}

The experiment was performed to evaluate the effectiveness of the TSTOP platform. The data were collected via interviews and online-surveys with 73 students from normal schools in Shangrao, China. The participants had studied relevant courses including teaching, education, psychology, modern educational technology before participating in this study, so they have enough domain knowledge and professional skills to complete the whole experiment. The data included students' motivation, interest, feedback, reflection and self-assessment.

\subsection{Procedure}

We first explained the purpose and significance of this study to the teachers and students, as well as set training objectives and process in the platform. Three rounds of training were then organized based on the TSTOP model.

The evaluation team was composed of six experienced professional teachers and five educational experts. The evaluation included experts' evaluation and teachers' evaluation, in addition to learners self and peer evaluation.

In addition to data collected through questionnaires and interviews, the video and document records, teaching plans, lesson descriptions, training processes, evaluations reports, and students' reflections were also collected from each round of training.

\section{Conclusions}

Based on the evaluation result, it was found that TSTOP model is an effective and efficient approach to pre-service teacher training in the following aspects. Firstly, it meets learners' needs and fits the trends of educational technology development. Secondly, using the TSTOP model, learners can imitate best practices according to films or videos, learning from peers and teachers. Thirdly, the TSTOP platform supports synchronous and asynchronous communications and discussions. This can strengthen cooperation and knowledge exchange in more depth and breadth, helping students grasp and understand tacit knowledge and experiences from experts. Fourthly, through the TSTOP platform, learners can publish their own ideas, lesson plans and suggestions, and reflections about the learning activities. They can also share useful teaching and learning materials, such as links and online courses on the platform. Finally, learners can upload their own teaching practices to the platform. Through repeated self-reflections and evaluations on lesson plans and teaching practices, students' teaching skills can be improved and developed in a solid way.

The functionalities of the platform will be further developed and enhanced, such as video management, indexing, commenting, and uploading and downloading lesson plans and teaching materials. Further evaluation will also be conducted accordingly. 


\section{References}

Bausch, S., \& Han, L. (2006). Podcasting gains an important foothold among U.S. adult online population [online]. Nielsen/ NetRatings. Retrieved from http://www.nielsennetratings.com/pr/pr_060712.pdf.

DeIker, P. V. (1990). Basic skills education in business and industry: Factors for success or failure. Contractor RePort, Office of Technology Assessment, United States Congress.

Felder, R. M., \& Brent, R. (2005). Understanding student differences. Journal of Engineering Education, 94(1), 57-72.

Gibbs, G., \& Coffey, M. (2004). The impact of training of university teachers on their teaching skills, their approach to teaching and the approach to learning of their students. Active Learning in Higher Education, 5(1), 87-100.

Lim, K. (2005). Now hear this - Exploring podcasting as a tool in geography education [online]. Nanyang Technological University. Retrieved from http://homepage.mac.com/voyager/brisbane kenlim.pdf.

Moursand, D., \& Bielefeldt, T. (1999). Will new teachers be prepared to teach in a digital age. International Society for Technology in Education \& Milken Exchange On Education Technology.U.S.A.

Yang, D., \& Wu, J. (1999). Some issues in the reform and development of teacher education and training in China. Teacher Development, 3(2), 157-172. 